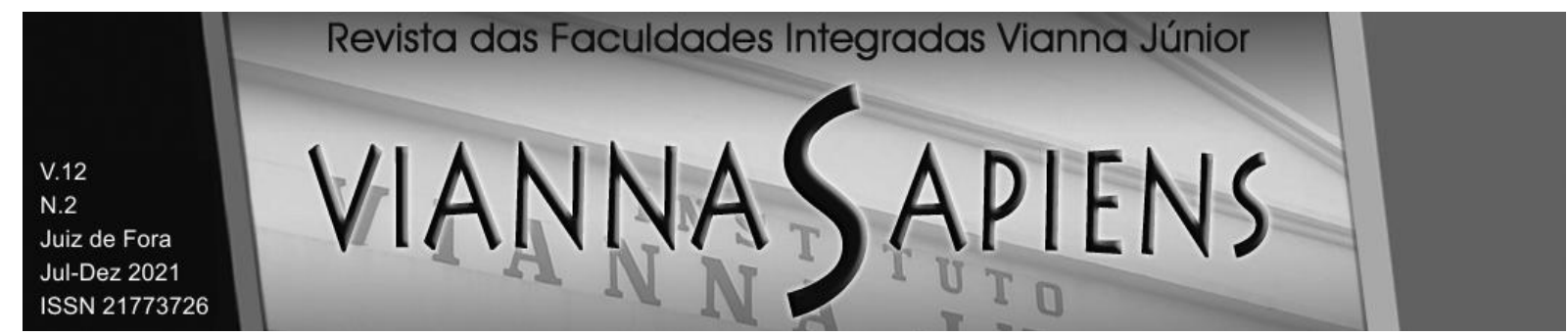

\title{
Análise do desempenho dos Fundos Imobiliários no Brasil entre 2017 e a pandemia Covid-19
}

DOI: 10.31994/rvs.v12i2.813

Eric Ivantes Dias ${ }^{1}$

Antônio Carlos Magalhães da Silva²

\section{RESUMO}

Em um contexto onde investidores pessoas físicas estão cada vez acessando o mercado imobiliário por meio dos fundos imobiliários, este estudo tem o objetivo de compreender os fundos imobiliários e sua dinâmica, apresentando ao pequeno investidor subsídios para tomada de decisão com informações relacionadas às variáveis que explicam seus retornos em momentos antes e diante da pandemia Covid-19, abrangendo os períodos de janeiro de 2017 a maio de 2021. A metodologia adotada foi a regressão linear de mínimos quadrados ordinários (MQO) para analisar as variáveis explicativas macroeconômicas e de mercado em relação a variável dependente IFIX. Para análise da amostra foi realizada uma regressão para o período amostral completo e posteriormente, uma segunda regressão foi realizada para o subperíodo amostral da pandemia Covid-19, com a conclusão de que, das variáveis adotadas, apenas os índices IMOB e o lbovespa apresentaram significância na explicação da variação do IFIX para as amostras.

\footnotetext{
${ }^{1}$ Mestrando em Administração e Desenvolvimento Empresarial (MADE/UNESA). Pós-graduado em Gestão em Administração Pública - UFF, Pós-graduado em Gestão Empresarial - AVM Faculdade, Graduado em Administração de Empresas - UFF. Email: ericdias_rj@yahoo.com.br - ORCID: 00000002-9855-3732

${ }^{2}$ Professor da UFF, Professor da Universidade Estácio de Sá (Unesa) do Mestrado em Administração e Desenvolvimento Empresarial (MADE/UNESA). Doutor em Engenharia de Produção - UFRJ, Mestre em Administração - Coppead/UFRJ, Graduado em Eng. de Produção - UFRJ, Graduado em Administração de Empresas - UERJ, Graduado em Ciências Contábeis - UERJ. Email: antonio.msilva@estacio.br - ORCID: 0000-0003-4497-3130
} 


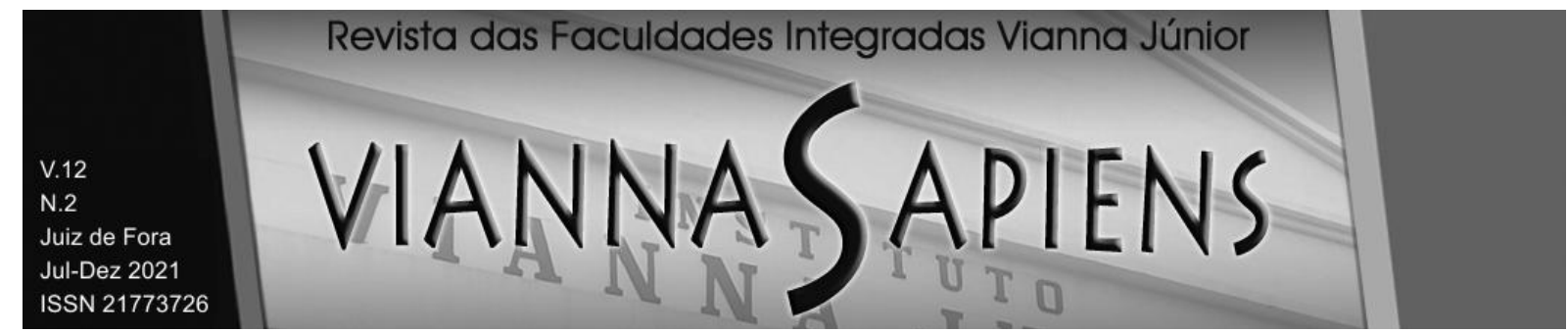

PALAVRAS-CHAVE: INVESTIMENTOS. MERCADO FINANCEIRO. FUNDOS DE INVESTIMENTOS IMOBILIÁRIOS. RENTABILIDADE.

\section{ABSTRACT}

In a context where individual investors are increasingly accessing the real estate market through real estate funds, this study aims to understand the real estate funds and their dynamics, presenting to the small investor subsidies for decision making with information related to the variables that explain their returns at times before and during the Covid-19 pandemic, covering the periods from January 2017 to May 2021. The methodology adopted was ordinary least squares (OLS) linear regression to analyze the macroeconomic and market explanatory variables in relation to the dependent variable IFIX. To analyze the sample, a regression was performed for the full sample period and subsequently, a second regression was performed for the sample subperiod of the Covid-19 pandemic, with the conclusion that, on the variables adopted, only the IMOB indexes and Ibovespa showed significance in explaining the variation of the IFIX for samples.

KEYWORDS: INVESTMENTS. FINANCIAL MARKET. REAL ESTATE INVESTMENT FUNDS. PROFITABILITY.

\section{INTRODUÇÃO}

Os fundos de investimentos imobiliários (Flls) foram criados pela Lei ํㅡㄴ 8.668/93 e regulamentados pela Instrução CVM o 472/08 (CVM, 2015). Esses fundos têm apresentado forte crescimento nos últimos anos. A recente trajetória de redução da taxa de juros tem estimulado o financiamento de imóveis e os investimentos nesse setor, fomentando a indústria dos fundos imobiliários, que vem 


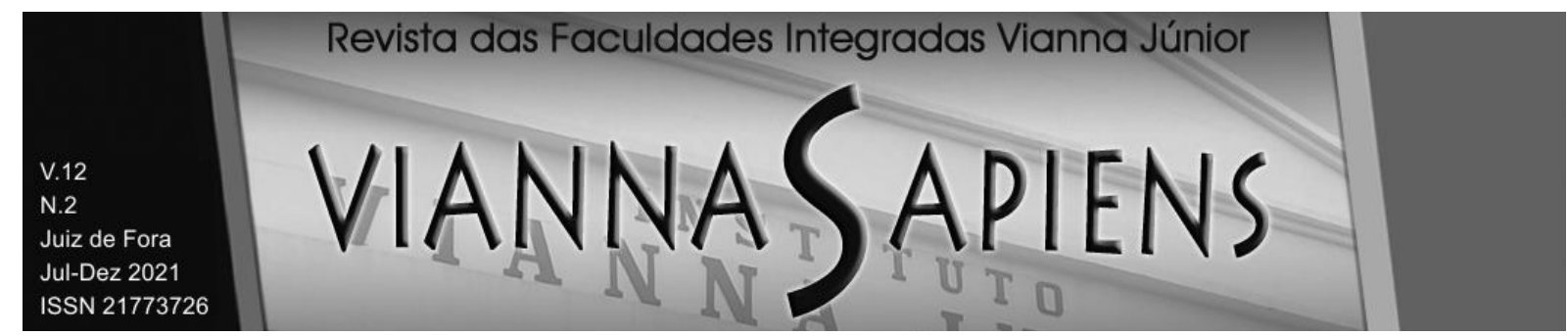

ganhando mais espaço no mercado brasileiro. Segundo o relatório de produtos de captação da ANBIMA (2014, p. 14),

[...] a trajetória declinante da taxa básica de juros da economia, somada às políticas de estímulo ao financiamento imobiliário e de recuperação da renda e emprego, alavancaram o mercado de imóveis, resultando em números crescentes de ofertas de fundos e demanda dos investidores.

Conforme Amato et al. (2007), tal redução das taxas de juros faz com que os investidores, de um modo geral, busquem produtos que possuam ativos com maior risco que permitam proporcionar maior rentabilidade ao seu portfólio. Conclui ainda que neste contexto, os fundos imobiliários são considerados uma opção que podem gerar ganhos fruto da valorização de suas quotas e também da distribuição de renda oriunda da exploração do lastro imobiliário.

Recentemente, novos investidores têm procurado por este tipo de produto já que ele possui características de renda fixa e renda variável. Segundo Yokoyama (2014), os fundos de investimento imobiliário combinam características tanto do mercado imobiliário, fonte de seus rendimentos, quanto do mercado de capitais, ambiente em que são negociados. A relação intrínseca dessa categoria de investimento com o mercado imobiliário, um dos favoritos dos brasileiros, é um dos fatores que justificam esse crescente interesse dos investidores nos últimos anos (CVM, 2015).

Para da Silva e Galdi (2015), os fundos imobiliários configuram como uma alternativa de investimento capaz de suprir a demanda de investidores que buscam um modelo de poupança mais estável a longo prazo e que as mudanças no cenário macroeconômico dos últimos anos, aliadas às mudanças na legislação, foram significativas para alavancar o mercado imobiliário brasileiro.

Os fundos configuram como investimento de acesso democrático ao mercado imobiliário, já que por menos de mil reais é possível acessar esse mercado. (MALACO, 2020) ressalta que o investimento via Flls perante a ótica do investidor são uma opção de investimento viável do ponto de vista do volume inicial necessário 


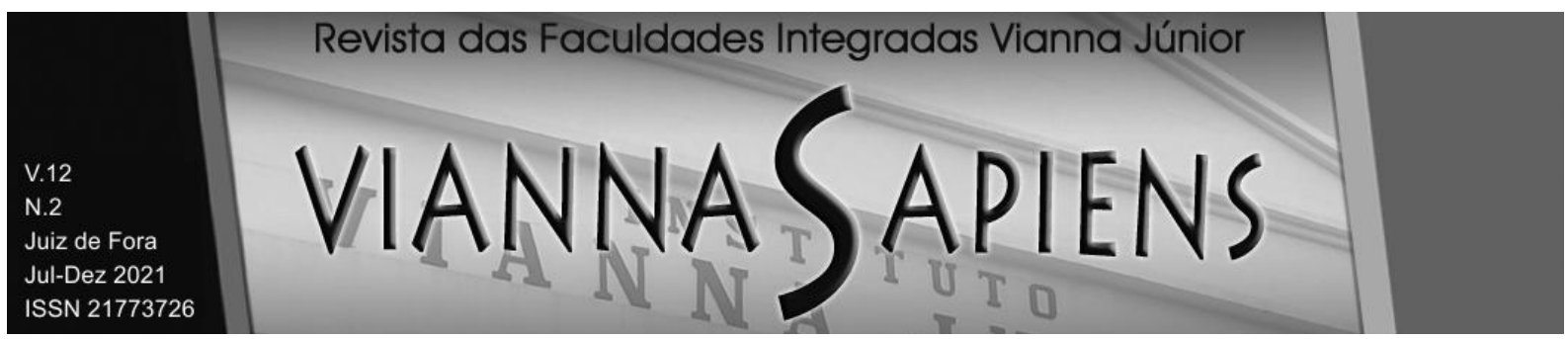

para aporte e tendo como lastro um ou mais imóveis. Catro (2012), ressalta que essa categoria de investimentos tornou possível que uma pessoa com um poder aquisitivo reduzido possa investir em um patrimônio sem a necessidade de comprar ou construir.

Este estudo busca aprofundar o entendimento sobre o mercado imobiliário dado tal cenário de maior interesse por investimentos nesse segmento dada a importância de os investidores compreenderem o comportamento desse mercado para que possam ser realizados investimentos de maneira mais segura viabilizando seu acesso ao mercado financeiro, bem como a diversificação da carteira dos investidores.

O objetivo do estudo é compreender a dinâmica dos fundos imobiliários e analisar as variáveis que explicam os retornos no período de janeiro de 2017 a maio de 2021 como forma de auxiliar o investidor pessoa física na tomada de decisões para diversificação dos seus investimentos. A metodologia adotada foi a regressão linear de mínimos quadrados ordinários (MQO) para analisar as variáveis explicativas macroeconômicas e de mercado considerando dois períodos amostrais para regressão, um para o período amostral completo e outro subperíodo amostral referente a pandemia Covid-19.

Dessa forma, a presente pesquisa está dividida em cinco segmentos, sendo o primeiro a introdução, seguida pela fundamentação teórica que se subdivide em quatro partes, sendo a primeira a conceituação dos fundos de investimentos, seguida pelos fundos imobiliários, suas classificações e posteriormente análise de estudos anteriores. O capítulo seguinte contempla os procedimentos metodológicos utilizados para alcançar os objetivos propostos e na sequência a análise dos resultados e as considerações finais. 


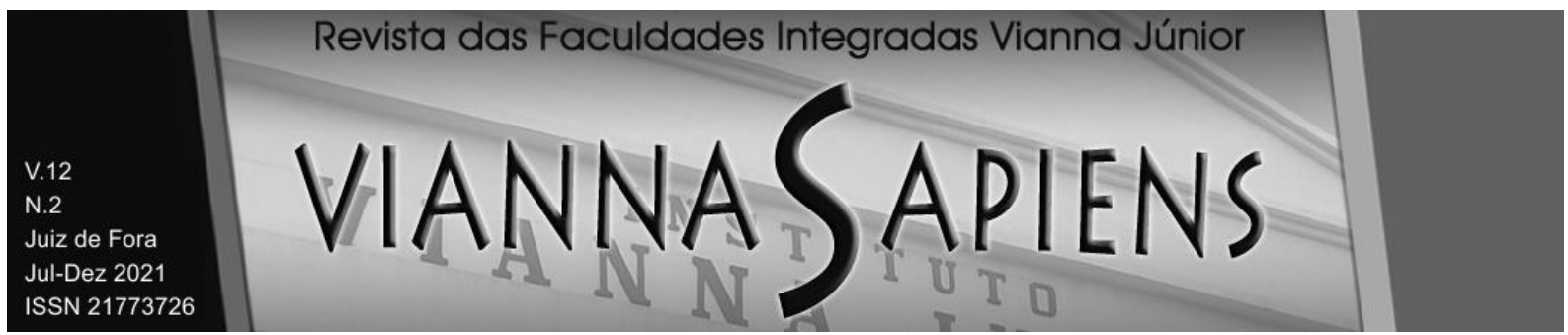

\section{FUNDOS DE INVESTIMENTO}

Fundos de investimento são instrumentos que unem investidores propiciando diversificação e acesso a produtos e carteiras que com mesmo montante não seria possível a um mesmo investidor. Conforme o caderno de fundos de investimentos CVM é possível que qualquer pessoa invista e administre a sua própria carteira de investimentos. No entanto, é igualmente possível investir em conjunto com outros investidores, por meio de uma estrutura formal de investimento coletivo chamada fundo de investimento (CVM, 2016)

Segundo a Comissão de Valores Mobiliários, um fundo de Investimento é uma comunhão de recursos constituída sob a forma de condomínio, destinado à aplicação em títulos e valores mobiliários, bem como em quaisquer outros ativos disponíveis no mercado financeiro e de capitais (BRASIL, 2004).

Os fundos de investimento podem ser formados como condomínios abertos, em que o resgate das cotas pode ser solicitado a qualquer tempo, ou fechados, em que o resgate só se dá no término do prazo de duração do fundo (CVM, 2016). Em síntese, um fundo aberto o investidor solicita resgate e o dinheiro entrará em sua conta, já no fundo fechado não há essa possibilidade, como é o caso dos fundos de investimentos imobiliários que não permitem resgates, mas sim a venda no mercado secundário como abordaremos a frente.

A soma dos recursos aplicados pelos investidores constitui o patrimônio do fundo, que é então dividido em cotas, o investidor torna-se o cotista. O patrimônio do fundo será investido em ativos financeiros por um profissional especializado, o gestor da carteira (CVM, 2016).

A comissão de valores mobiliário (CVM) conceitua os fundos de investimentos em sua instrução 555/14 quanto à composição de sua carteira em fundo de renda fixa, fundo de ações, fundo multimercado e fundo cambial. Tais classificações delimitam as possibilidades de aplicações bem como percentuais de alocações e regras de composição das carteiras desses fundos (BRASIL, 2014, art. 108.) 


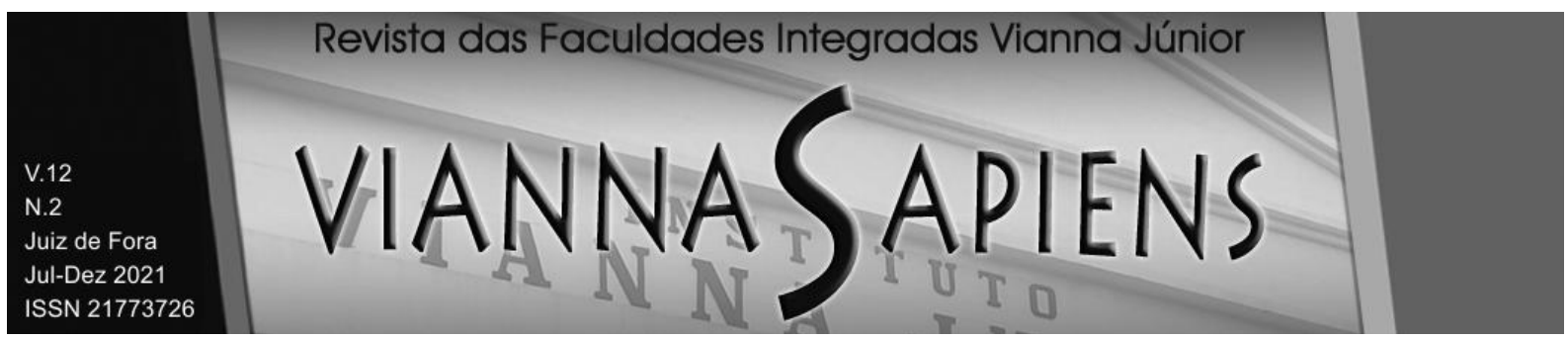

\subsection{Fundos de investimento imobiliários}

Os fundos imobiliários são fundos constituídos sob a forma de condomínio fechado, o que significa que não há possibilidade de resgate de cotas, os titulares de cotas de Flls precisam comercializar suas cotas no mercado secundário, diferente dos fundos abertos que permitem resgate de suas cotas a qualquer momento. Os Fundos de Investimentos Imobiliários Fll representam uma forma de captação de recursos por meio de cotas representativas de valores mobiliários de renda variável. Essas cotas são parcelas de valores mobiliários não resgatáveis, tendo que vender a terceiros para retomar o investimento (MIZUNO et al., 2011)

Os Flls são um veículo, administrado por uma instituição financeira, que recebe recursos de diversos investidores, recursos estes que devem ser majoritariamente aplicados em empreendimentos em construção ou aquisição de imóvel, para futura locação ou arrendamento (STEFFEN, 2015). O investidor será cotista do fundo e os valores recebidos dos aluguéis ou outros rendimentos do fundo serão distribuídos aos cotistas mensalmente.

O investimento é efetivado através da aquisição de cotas, já o retorno do capital investido se dá por meio de diferentes formas, conforme explica (AMATO et al., 2005) as possibilidades de retorno são oriundas da distribuição de resultados, da venda da quota, em bolsa de valores ou no mercado de balcão, ou da dissolução do fundo com a venda dos seus ativos e a distribuição proporcional do patrimônio aos cotistas.

Segundo a ANBIMA (2014), os Flls podem investir em empreendimentos imobiliários no país, em diversos segmentos do setor imobiliário, como comercial, corporativo, residencial e industrial, podendo investir desde shoppings centers, galerias, hotéis, a edifícios residenciais, dentre outros. A rentabilidade e os riscos de cada fundo são, em grande medida, relacionados com os tipos de ativos em que pretende investir, razão pela qual é importante que o investidor conheça a política de investimentos dos fundos de seu interesse (CVM, 2015). 


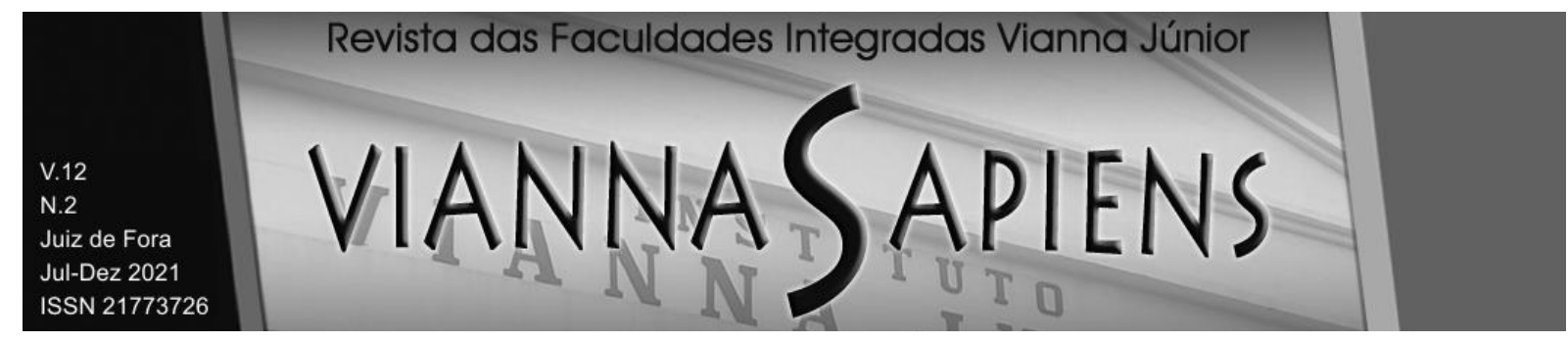

Considerando o potencial de diversificação dos fundos imobiliários em relação a outros tipos de investimento e tendo em vista que a inclusão de fundos imobiliários pode ter um potencial diversificador numa carteira multi-ativo (YOKOYAMA, 2014).

A relevância do tema é reforçada dado o peso do setor imobiliário na economia brasileira de $12 \%$ do PIB, havendo bastante espaço para a manutenção da trajetória de crescimento dos fundos imobiliários considerando a ampliação da sua participação na indústria de fundos e o crescente interesse dos investidores (ANBIMA, 2014).

Figura 1 - Patrimônio Líquido $\mathrm{R}$ \$ milhões Fundos Imobiliários

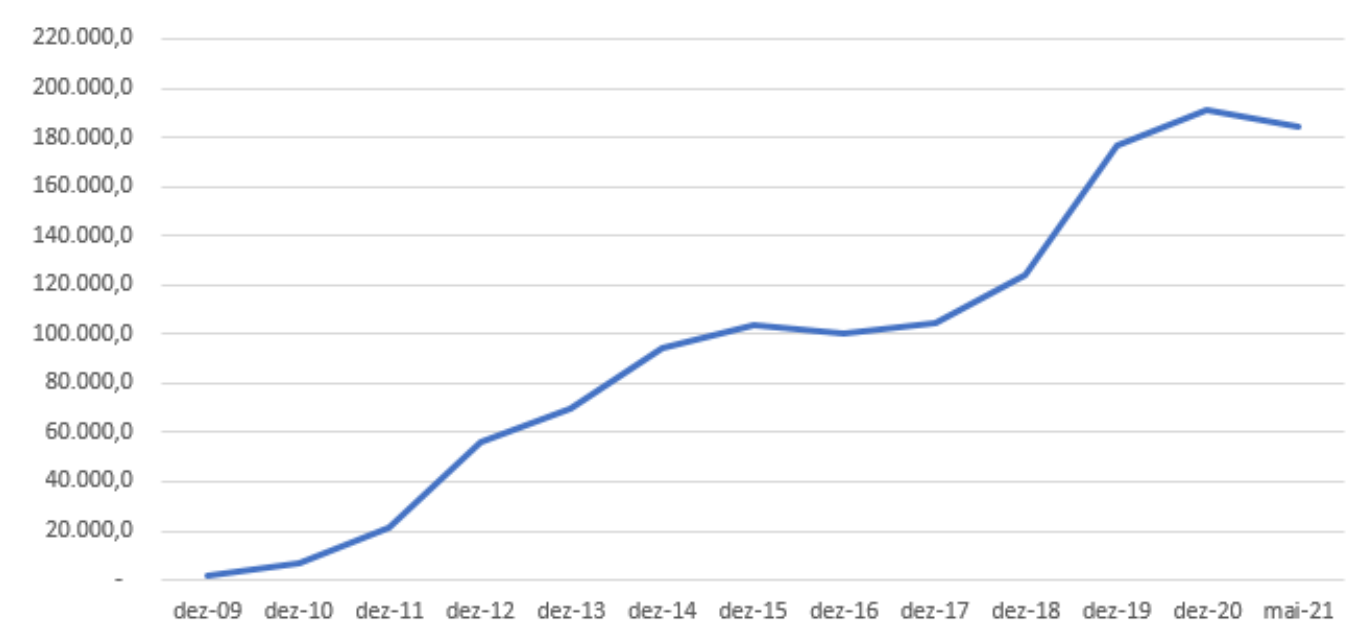

Fonte: elaborado pelo autor.

\subsection{Classificação dos fundos imobiliários}

A ANBIMA desenvolveu uma classificação para fundos imobiliários em um modelo que os divide em dois níveis (ANBIMA, 2015). O primeiro determina o objetivo do fundo de acordo com a finalidade do investimento, nomeado pela ANBIMA de mandato, totalizando cinco tipos de estratégias:

- Desenvolvimento para renda: construção de imóveis que serão locados pelo fundo; 


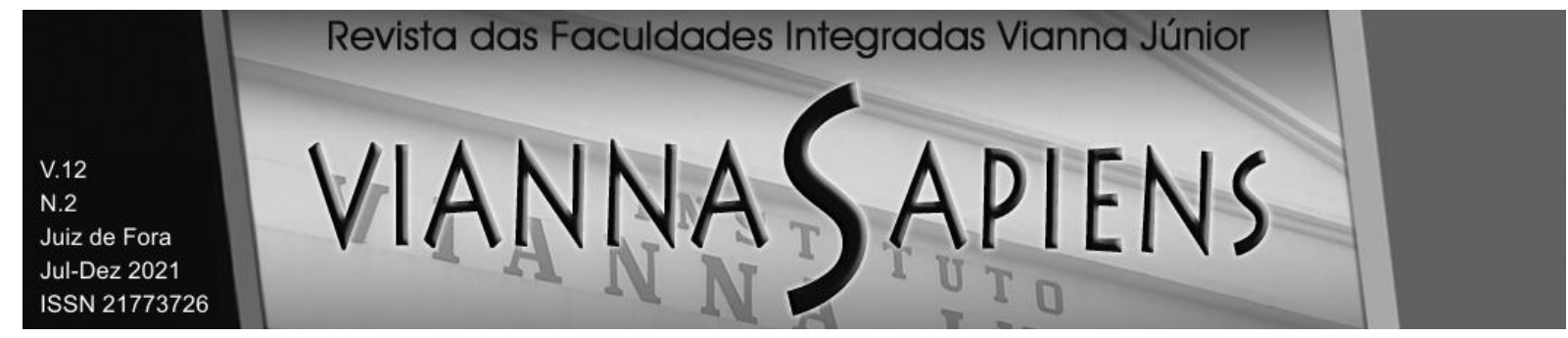

- Desenvolvimento para venda: construção de imóveis que serão vendidos pelo fundo;

- $\quad$ Renda: compra de imóveis prontos que serão locados pelo fundo;

- Títulos Valores Mobiliários: compra de títulos como CRI, LCI, LIG, cotas de FII etc.;

- $\quad$ Híbridos: diversas estratégias sem que nenhuma seja preponderante.

O segundo nível classifica o fundo por tipo de gestão: passiva ou ativa. A gestão passiva contempla fundos que especificam em seus regulamentos o imóvel ou o conjunto de imóveis que comporá sua carteira de investimento ou aqueles que têm por objetivo acompanhar um indicador do setor, por exemplo, o IFIX (Índice de Fundos de Investimento Imobiliário). Já para gestão ativa a ANBIMA denomina todos os fundos que não seguem os critérios da gestão passiva (ANBIMA, 2015).

Há também o segmento de atuação dos fundos que diz respeito ao ramo do mercado imobiliário em que ele atua com base no regulamento do fundo. Mingione e Britto (2018) elencam onze classificações;

1. Agências

2. Educacional

3. Híbrido

4. Hospital

5. Hotel

6. Lajes Corporativas

7. Logística

8. Residencial

9. Shoppings

10. Títulos e Valores Mobiliários

11. Outros 


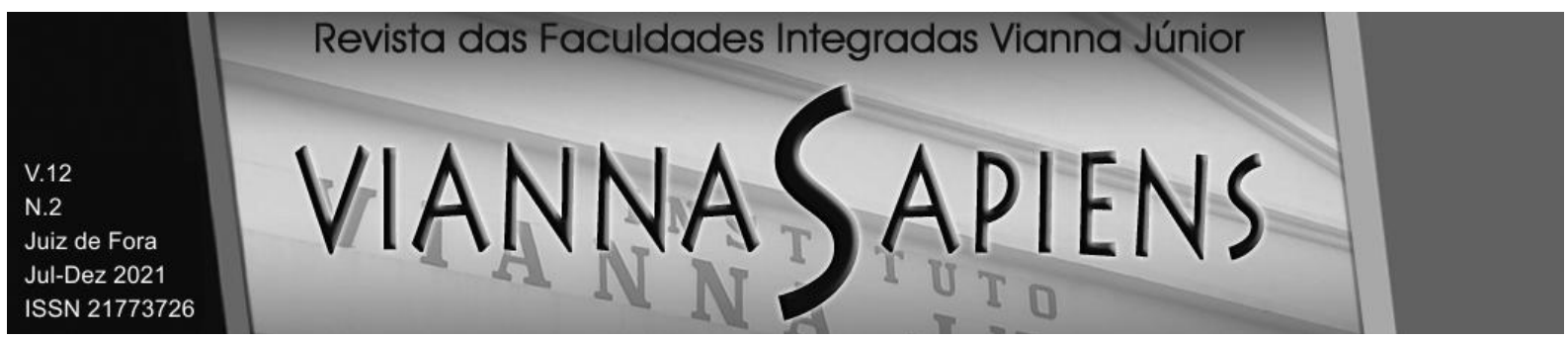

\section{ESTUDOS ANTERIORES}

Oliveira e Milani (2020) elaboraram um estudo para compreender as oscilações do IFIX com índices macroeconômicos e de mercado obtendo como resultado que o índice Ibovespa é o que explica o retorno dos Fundos Imobiliários da amostra analisada entre janeiro de 2012 a dezembro 2017. A análise foi realizada por meio de regressão stepwise com a variável dependente IFIX e explanatórias sendo índices de renda fixa, inflação e do mercado imobiliário. O IFIX assim como Ibovespa são índices, criados pela bolsa como um parâmetro de desempenho para as carteiras dos fundos deste segmento, para os Flls bem como uma carteira teórica de ações para o lbovespa (ANBIMA, 2014).

Durante o período de crise de 2014 a 2017, Mingione e Britto (2018) fizeram uma comparação de indicadores de retorno e risco para uma amostra de 78 Flls com os índices IPCA, CDI e Ibovespa para um período de estudo de julho/2013 a dezembro/2017 e concluíram ainda que para tal período de crise Flls não foram a melhor opção para proteção de capital pois o CDI apresentou retornos superiores nesse período. Em termos de risco $\mathrm{x}$ retorno, em geral concluíram que os Flls seriam mais atrativos do que o lbovespa e menos atrativo do que o CDI.

Figueiredo Filho e Akkari (2019) avaliaram o impacto de indicadores macroeconômicos no comportamento do valor de negociação das cotas de 13 fundos imobiliários com diferentes estratégias no período de 2013 a 2018. Os estudos analisaram a evolução do valor das cotas com as taxas de juros, inflação, IFIX, Ibovespa e outros. Uma das conclusões foi a de que os fundos sofrem impactos de magnitude diferente um do outro, dependendo não somente de sua estratégia adotada, mas também de seu portfólio, ressaltando a importância de observar a composição dos fundos.

Steffen (2015) em seu estudo sugeriu que há uma influência significante da variação da bolsa de valores na análise de uma carteira geral de Flls, porém, quando são analisadas carteiras compostas por Flls com características específicas, esta influência diminui. Os Flls que visem ao desenvolvimento imobiliário, voltados 


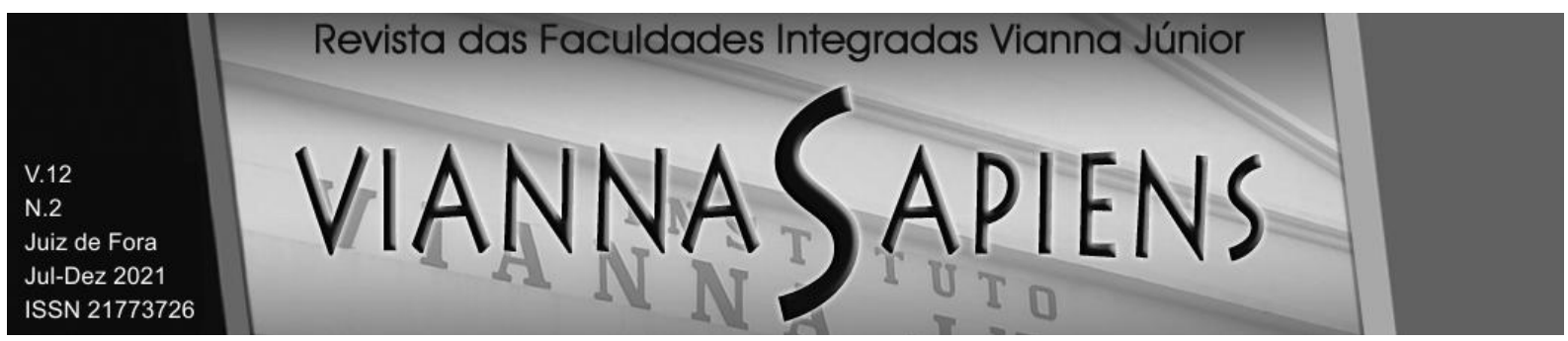

ao mercado residencial e com baixas taxas de administração devem apresentar desempenho superior em relação aos demais foi a conclusão de outro estudo (BARRETO, 2016).

O estudo concluiu como estatisticamente relevante a espera de uma maior rentabilidade nos fundos de gestão ativa, sem imóvel definido, cuja política de investimento visa lajes corporativas localizadas nos grandes centros urbanos. Identificou também que fundos que investem em títulos de recebíveis imobiliários (CRls, LHs e LCls) não apresentaram rentabilidade estatisticamente diferente dos demais Flls de gestão ativa (FIORINI, 2012).

Tognini e Alencar (2019) concluíram que uma gestão ativa teve um resultado superior a portfólio hipotético comparado ao de gestão passiva e elencam benefícios do fundo de fundo que analisaram no estudo. O papel teve o benefício de investir simultaneamente em diversos segmentos se beneficiando não somente do investimento no mercado imobiliário, mas também da mudança de seu portfólio e dos lucros auferidos com as operações de compra e venda de cotas de Flls, consequentemente apresentando desempenhos positivos e superiores à um benchmark em um horizonte de curto e médio prazo. Contudo, é válido ressaltar a limitação do estudo com apenas uma unidade de um fundo de fundo, analisado no período de março de 2016 a março de 2019.

Rodrigues (2012) sinaliza em seu estudo o custo de não possuir alocação em investimento imobiliário a uma taxa de 1,19 a 1,78\% a.a. como custo de não investir em imóveis trazido ao investidor avesso ao risco. Corroborando a relevância do estudo de subsidiar entendimento do comportamento das variáveis que afetam os fundos imobiliários, facilitando a decisão do investidor pessoa física comum a não pagar tal custo conforme identificado pelo autor do estudo, trazendo diversificação a sua carteira. 


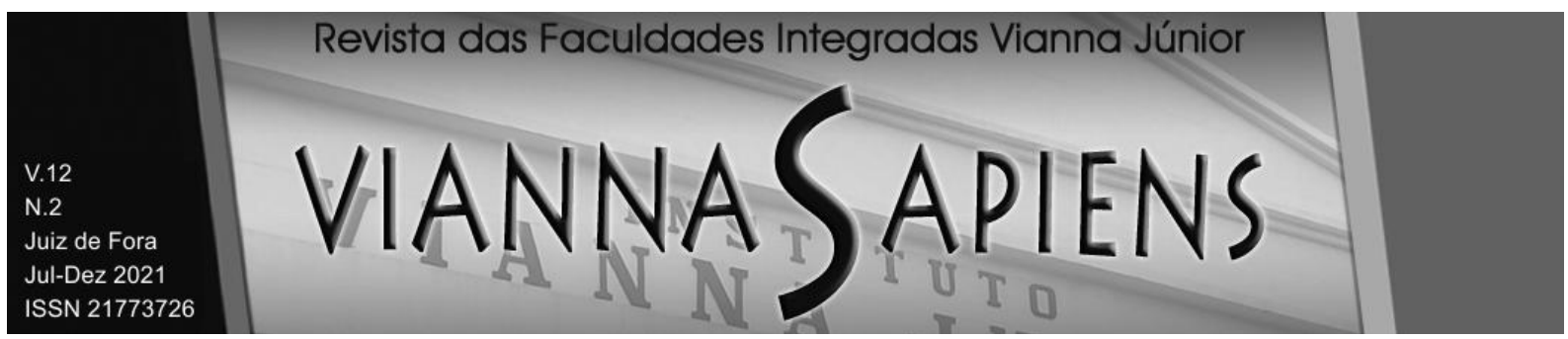

\section{PROCEDIMENTOS METODOLÓGICOS}

O presente estudo adota a abordagem quantitativa, pois busca tratar estatisticamente os dados colhidos, com objetivo de verificar as relações hipotéticas da pesquisa (MARTINS; THEÓPHILO, 2009). Quanto aos fins, este trabalho é explicativo, já que busca explicar as relações causais entre as variáveis (VERGARA, 2016), sendo utilizado o software Gretl para a análise dos dados.

A pesquisa documental foi o procedimento adotado para a coleta de dados, ela utiliza outras fontes documentais primárias para a construção do entendimento sobre o objeto de estudo proporcionando uma melhor visão da temática (GIL, 2016).

Considerando o objetivo da pesquisa foram utilizados para o estudo índices macroeconômicos e de mercado. As variáveis selecionadas para o estudo foram elencadas na literatura em estudos anteriores que também buscavam explicar a variação dos Flls. Foram coletados dados mensais para a amostra selecionada de janeiro de 2017 a maio de 2021, considerada adequada aos fins que esse trabalho se propõe.

Como índice de mercado foi utilizado o IFIX que é elaborado pela B3 e tem como objetivo ser um indicador de referência de desempenho médio dos fundos imobiliários negociados na B3 (HIRANO, 2018). Assim como para (OLIVEIRA; MILANI, 2020) para atender ao objetivo da pesquisa, a variação do Índice IFIX foi utilizado como proxy da rentabilidade dos fundos imobiliários, sendo a variável dependente deste estudo.

As variáveis macroeconômicas do estudo contemplam a Selic, que representa a taxa de juros da economia. O IGP-M, índice geral de preço do mercado, publicado pela FGV, é o índice de inflação mais comumente utilizado para correção de contratos de locação imobiliária, assim como o IPCA, índice de preço ao consumidor, que é o índice oficial de inflação no país (YOKOYAMA, 2014).

Ainda como índice de mercado foi também utilizado o IMOB, Índice B3 Imobiliário, que mede o desempenho das ações das principais empresas do setor imobiliário negociadas em bolsa de valores. Em seu estudo, Hirano (2018) utilizou 


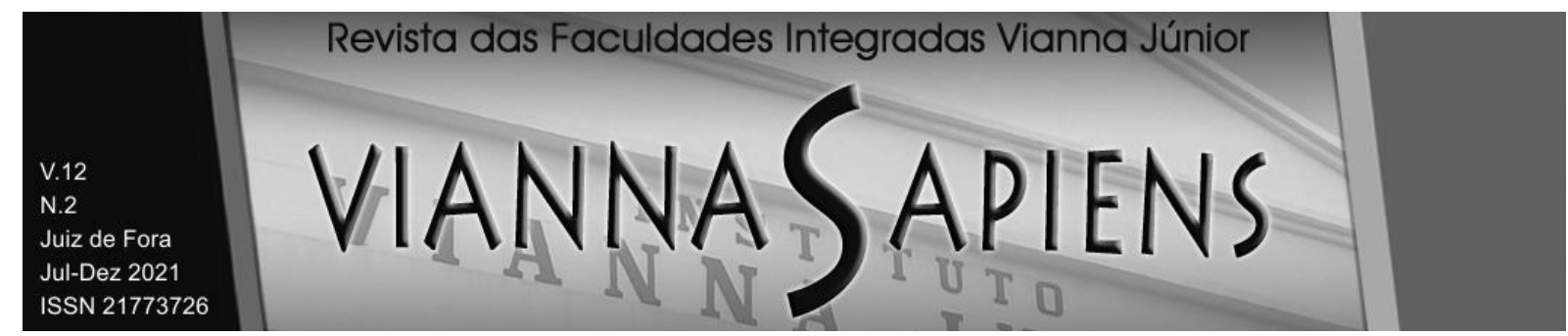

como forma de replicar o movimento dos investidores de aversão ao risco ou de tomada de risco, o índice lbovespa, elaborado pela B3 e que tem o objetivo de replicar o desempenho médio das ações negociadas na Bovespa, que será também adotado nesse estudo.

\section{ANÁLISE dOS RESULTADOS}

Foi utilizada uma regressão linear de mínimos quadrados ordinários (MQO) para o período amostral completo. Posteriormente, uma segunda regressão foi realizada para o subperíodo específico da pandemia Covid-19, a partir da declaração de pandemia pela OMS ao fim da amostra, compreendido entre março de 2020 e maio de 2021.

De acordo com Dalson Filho et al. (2011), o IFIX representa a variável dependente, ou seja, aquilo que queremos explicar e entender. As demais variáveis independentes são aquilo que o pesquisador acredita que pode ajudar a explicar a variação do IFIX.

\subsection{Regressão linear com amostra completa}

A seguir é apresentada a matriz de correlação de Pearson das variáveis testadas no modelo. 


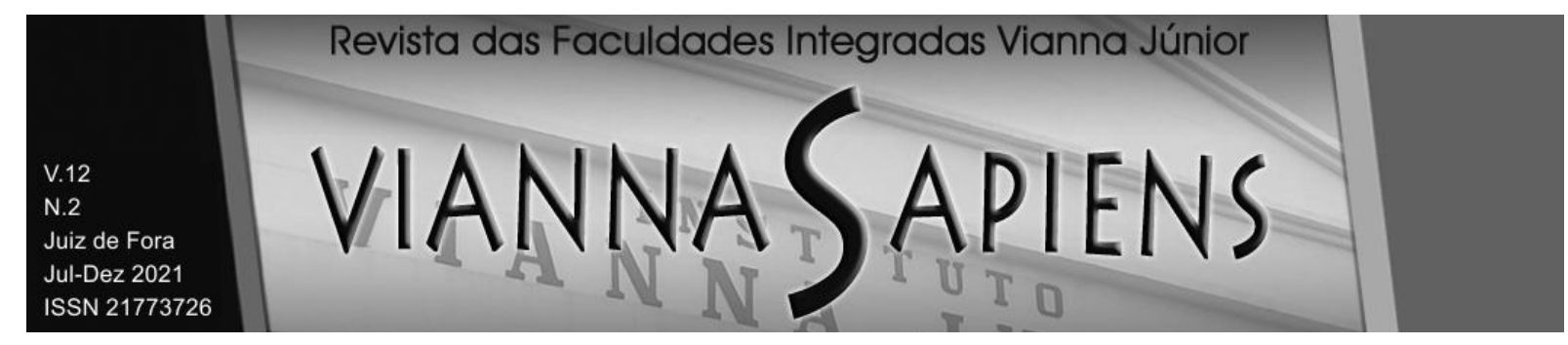

Figura 2 - Matriz Correlação para amostra completa.

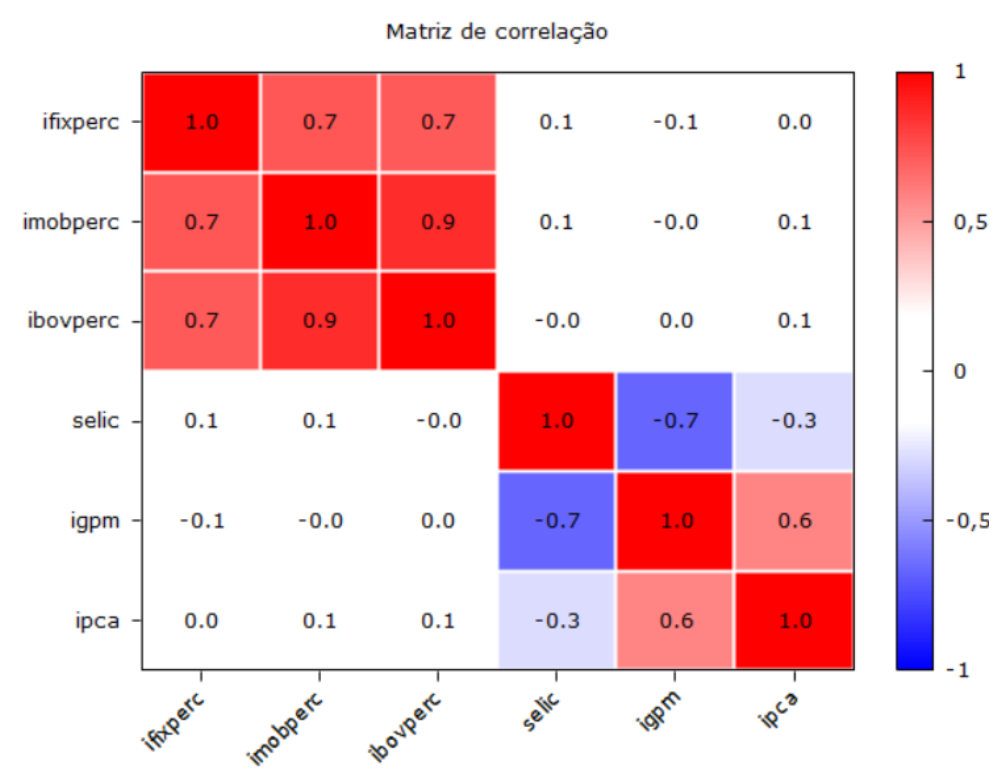

Fonte: Elaborado pelo autor no software Gretl.

Para o período completo da amostra a variável IFIX demonstrou possuir maior correlação com os índices IMOB e o IBOV, em menor grau com o Selic e IPCA e correlação negativa com o IGP-M, já nos estudos de Yokoyama (2014), verificou-se que os fundos imobiliários daquela amostra, de 2008 a 2013, possuíam baixa correlação com as demais variáveis de retorno analisadas no modelo que contemplavam variáveis como o IBOV, IMOB e Selic.

Tabela 1 - Resultado do Modelo de Mínimos Quadrado Ordinários para amostra completa.

Modelo 1: MQO, usando as observações 2017:01-2021:05 ( $T=53)$

Variável dependente: ifixperc

$\begin{array}{lcccc} & \text { Coeficiente } & \text { Erro Padrão } & \text { razão-t } & p \text {-valor } \\ \text { const } & 0,329953 & 1,28418 & 0,2569 & 0,7983 \\ \text { ipca } & 0,00781695 & 1,17933 & 0,006628 & 0,9947 \\ \text { igpm } & -0,257236 & 0,441331 & -0,5829 & 0,5628 \\ \text { selic } & 0,438927 & 2,05654 & 0,2134 & 0,8319 \\ \text { ibovperc } & 0,188812 & 0,0989056 & 1,909 & 0,0624\end{array}$ *




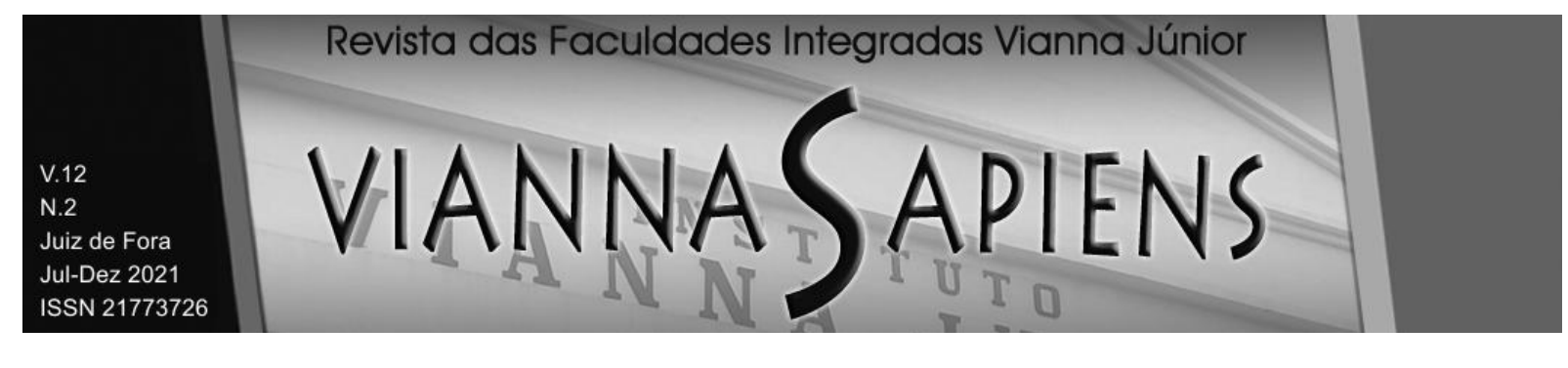

\begin{tabular}{|c|c|c|c|}
\hline imobperc & 4863 & 2,054 & 0,0456 \\
\hline Média var. dependente & 0,846422 & D.P. var. dependente & 3,583113 \\
\hline $\begin{array}{l}\text { Soma resíd. } \\
\text { quadrados }\end{array}$ & 291,0425 & E.P. da regressão & 2,488452 \\
\hline R-quadrado & 0,564055 & R-quadrado ajustado & 0,517677 \\
\hline$F(5,47)$ & 12,16233 & P-valor $(F)$ & $1,38 e-07$ \\
\hline $\begin{array}{l}\text { Log da } \\
\text { verossimilhança }\end{array}$ & $-120,3379$ & Critério de Akaike & 252,6759 \\
\hline Critério de Schwarz & 264,4976 & Critério Hannan-Quinn & 257,2220 \\
\hline rô & $-0,040945$ & Durbin-Watson & \\
\hline
\end{tabular}

Fonte: Elaborado pelo autor no software Gretl.

Por meio da análise do Fator de Inflação da Variância (FIV) foi verificado que não há existência de valores representativos de problemas de colinearidade. O Rquadrado, medida de associação, que é o coeficiente de correlação ao quadrado também conhecido como o coeficiente de determinação, indica o percentual de variação total do IFIX explicado pelo modelo de regressão consistindo das variáveis independentes (Hair et al, 2009), significando que as variáveis explicam em aproximadamente $56,40 \%$ da variável dependente IFIX.

Os resultados apontam que o índice IMOB explica o retorno dos fundos de investimento imobiliários, representados pelo índice IFIX, com coeficiente de aproximadamente 0,14 . Logo, no período analisado, a cada $1 \%$ de aumento do Índice IMOB, houve um aumento de $0,14 \%$ nos Fundos Imobiliários representados pelo IFIX.

O P-valor apresentou níveis de significância estatística representativos de 5\% para a variável IMOB e 10\% para variável IBOV. Não houve significância relevante para as variáveis IPCA, Selic e IGP-M o que significa que para o estudo tais variáveis são as que menos explicariam a variação do IFIX para a amostra. 


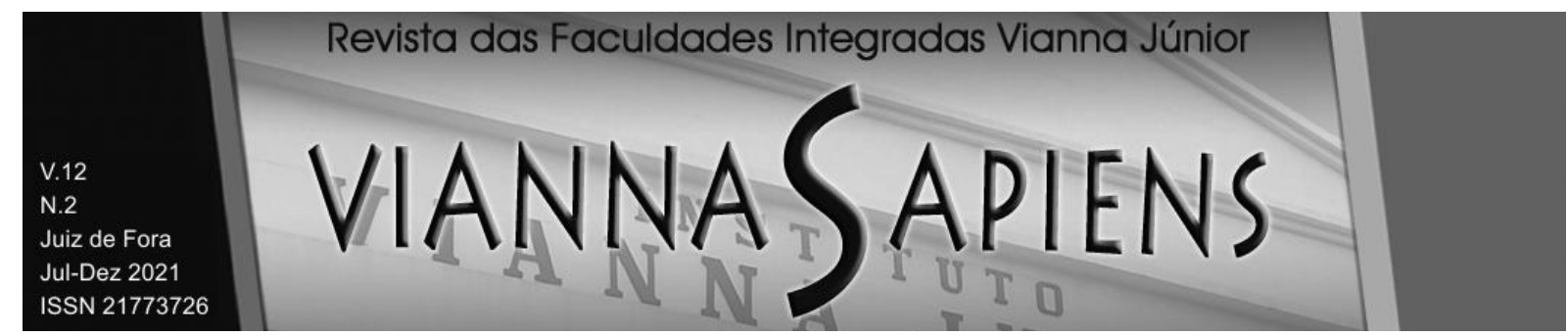

\subsection{Regressão linear com subamostra}

Considerando que a Organização Mundial de Saúde (OMS) declarou a pandemia no dia 11 de março de 2020, doença causada pelo novo coronavírus (Sars-Cov-2) e considerando ainda que tal declaração trouxe impacto mundial a sociedade bem como ao mercado financeiro.

Dado o novo cenário foi selecionado um subperíodo amostral com dados de março de 2020 a maio de 2021 para analisar se houve alteração na correlação e no comportamento das variáveis em relação à amostra completa. Após uma estimação preliminar de regressão, a variável Selic foi considerada significativa. Porém, verificou-se, através do Fator de Inflação da Variância (FIV), problema na regressão devido à multicolinearidade entre as variáveis IMOB e IBOV com correlação 1 entre as variáveis. Foram realizadas duas novas regressões, alternando a utilização das variáveis IMOB e IBOV. Ambas regressões apresentaram significância a 1\% para as variáveis IMOB e IBOV e 5\% para Selic.

A tabela 2 apresenta os coeficientes estimados pela regressão realizada com o subperíodo amostral que vai de março de 2020 a maio de 2021, totalizando 15 observações.

Tabela 2 - Resultado do Modelo de Mínimos Quadrado Ordinários para subamostra.

Modelo 2: MQO, usando as observações 2020:03-2021:05 ( $T=15)$ Variável dependente: ifixperc

$\begin{array}{lccccc} & \text { Coeficiente } & \text { Erro Padrão } & \text { razão- } t & p \text {-valor } & \\ \text { const } & 8,59730 & 4,00272 & 2,148 & 0,0573 & * \\ \text { ipca } & -3,23539 & 1,88701 & -1,715 & 0,1172 & \\ \text { igpm } & -0,0963244 & 0,710882 & -0,1355 & 0,8949 & \\ \text { selic } & -38,1235 & 14,9442 & -2,551 & 0,0288 & * \\ \text { ibovperc } & 0,312895 & 0,0696677 & 4,491 & 0,0012 & * *\end{array}$

$\begin{array}{lrll}\text { Média var. dependente } & -0,220776 & \text { D.P. var. dependente } & 4,843043 \\ \text { Soma resíd. } & 68,72389 & \text { E.P. da regressão } & 2,621524 \\ \text { quadrados } & & & \\ \text { R-quadrado } & 0,790713 & \text { R-quadrado ajustado } & 0,706998 \\ \text { F(4, 10) } & 9,445296 & \text { P-valor }(F) & 0,001989\end{array}$




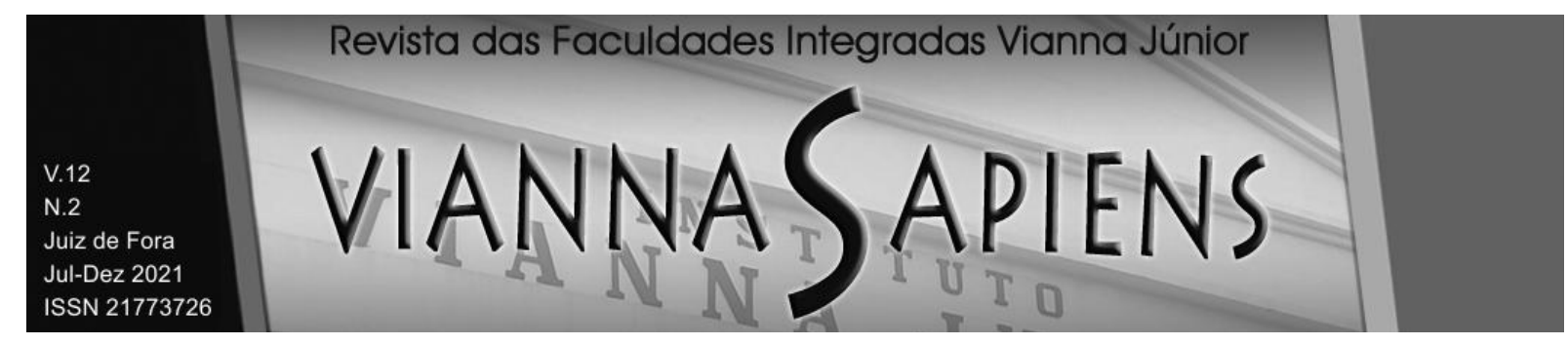

$\begin{array}{lrlr}\text { Log da } & -32,69943 & \text { Critério de Akaike } & 75,39886 \\ \text { verossimilhança } & & & \\ \text { Critério de Schwarz } & 78,93911 & \text { Critério Hannan-Quinn } & 75,36114 \\ \text { rô } & -0,566677 & \text { Durbin-Watson } & 3,035764\end{array}$

Fonte: Elaborado pelo autor no software Gretl.

O estudo observou que para o período da pandemia Covid-19 as variáveis que afetam o IFIX diferem em relação a análise da amostra completa uma vez que houve aumento da significância para as variáveis IMOB e IBOV, e também para Selic, porém com menor significância, o que sugere que em momentos de crises pode haver uma mais significativa relação entre o IFIX e as variáveis IBOV e IMOB.

Figura 5 - Matriz Correlação para subamostra.

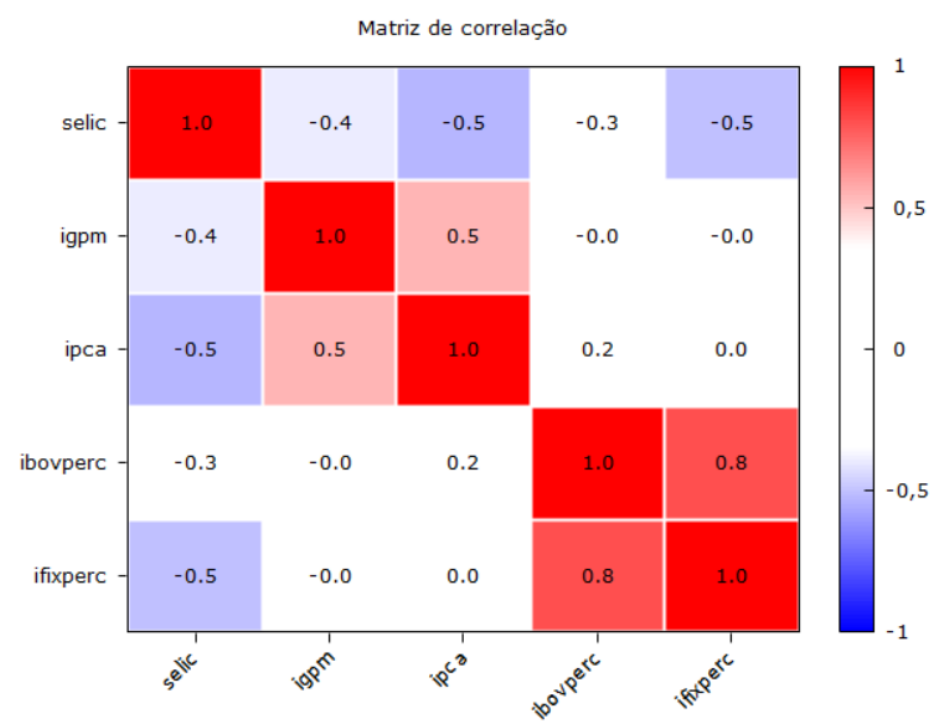

Fonte: Elaborado pelo autor no software Gretl.

A matriz de correlação para o subperíodo amostral apresentou relativa diferença para amostra completa uma vez que o IPCA e o IGP-M não apresentam correlação e as variáveis IMOB e IBOV apresentaram correlação de 0,8 similares a análise da amostra completa, quando apresentaram o valor de 0,7 enquanto a correlação com a Selic se mostrou negativa. 


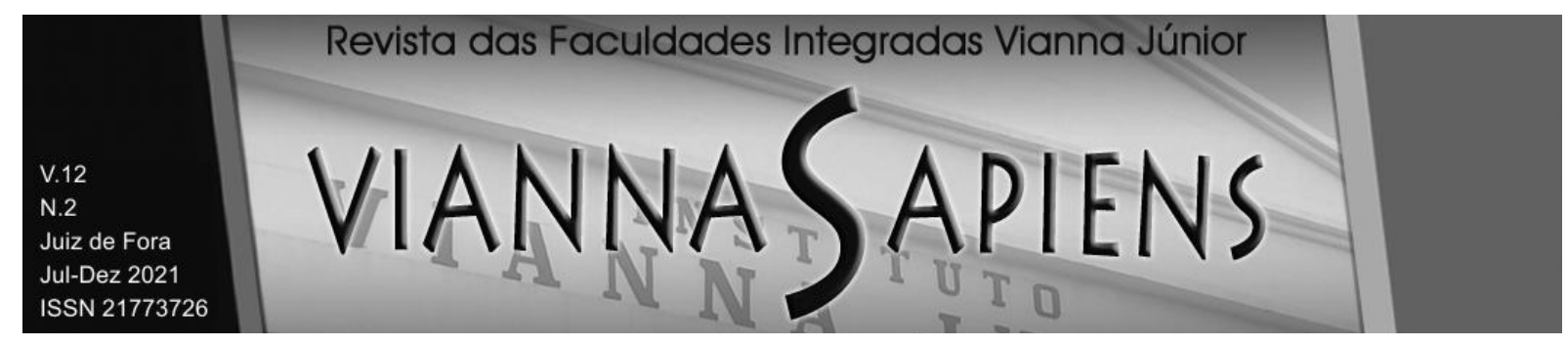

CONSIDERAÇÕES FINAIS

O objetivo deste estudo foi abordar as variáveis que explicam os retornos dos fundos imobiliários em momentos antes e diante da pandemia Covid-19 abrangendo os períodos de janeiro de 2017 a maio de 2021. Foram coletados dados de índices de mercado e macroeconômicos.

Dentre as variáveis explicativas, o resultado indica que os índices IMOB e IBOV apresentam o maior efeito sobre a variação do IFIX para a amostra completa, o que é acentuado no período da pandemia Covid-19 já que essas variáveis apresentaram maior significância para o período da pandemia, o que parcialmente também foi observado em estudos anteriores que concluíram que o índice lbovespa é a única variável que explica o retorno dos Fundos Imobiliários.

Este estudo contribuiu para a tomada de decisão dos pequenos investidores uma vez que subsidia o pequeno investidor com análise de que o IFIX não tem sua dinâmica impactada somente conforme o IBOV, como em estudos anteriores, mas também com relação às empresas do setor imobiliário, neste estudo representado pelo índice IMOB, e que não há associação com significância dos Flls com índices de inflação.

O estudo contribuiu para o investidor identificar as variáveis que impactam nos fundos imobiliários em um momento em que há um grande fluxo de pessoas físicas entrando no mercado de renda variável e acessando este tipo de produto que é uma oportunidade de acesso ao mercado imobiliário com baixo custo de aplicação inicial possibilitando a diversificação e a minimização de risco do seu capital investido.

Como sugestão de estudos futuros, recomenda-se utilização de testes de indicadores inflacionários com janelas de defasagem para verificar os impactos na variável dependente. Como sugestão de aprimoramento, recomenda-se a incorporação da análise do IFIX ou de outros setores de fundos imobiliários específicos com uma maior base de dados incorporando também maiores subperíodos amostrais considerando ciclos econômicos e momentos de crise. A 


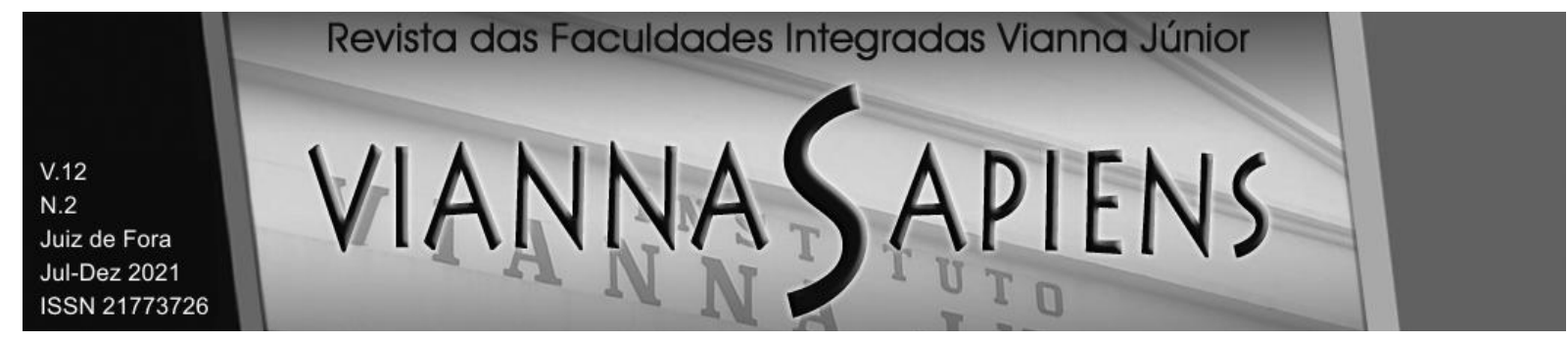

análise do subperíodo amostral da pandemia Covid-19 foi feita em um período muito curto de tempo, já que a pandemia ainda persiste e cabe ressaltar que a relevância das variáveis do modelo podem se alterar no decorrer da pandemia.

\section{REFERÊNCIAS}

AMATO, Fernando Bontorim et al. Estratégia de aplicação em fundos imobiliários como diversificação de investimentos: uma análise do desempenho recente e seus fatores de influência. VIII Seminário em Administração, FEA-USP, São Paulo, 2005.

. et al. Impacto da Taxa de Juros Reais no Brasil no Valor dos Imóveis para Renda: o caso dos Fundos de Investimento Imobiliário negociados em Bolsa de Valores. Latin American Real Estate Society (LARES), 2007.

ANBIMA. Estudos especiais - Produtos de Captação. Fundos de Investimento Imobiliário. Associação Brasileira das Entidades dos Mercados Financeiro e de Capitais (ANBIMA), 2014. Disponível em: http://portal.anbima.com.br/informacoestecnicas/estatisticas/fundos-deinvestimento-imobiliario/Documents/estudosespeciais-produtos-de-captacaofundos-de-investimento-imobiliario.pdf. Acesso em: 07 jul. 2021.

. Deliberação no 62. Conselho de regulação e melhores práticas de

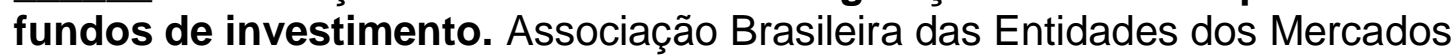
Financeiro e de Capitais (ANBIMA). Disponível em: https://www.anbima.com.br/data/files/9F/21/46/B7/FBC575106582A275862C16A8/D eliberacaoN_2062_ClassificacaoFII_1_.pdf. Acesso em: 09 de jul. 2021.

Fundos imobiliários ganham classificação inédita no mercado. Associação Brasileira das Entidades dos Mercados Financeiro e de Capitais (ANBIMA). Disponível em:

https://www.anbima.com.br/pt_br/noticias/fundos-imobiliarios-ganham-classificacaoinedita-no-mercado.htm. Acesso em: 09 de jul. 2021. 


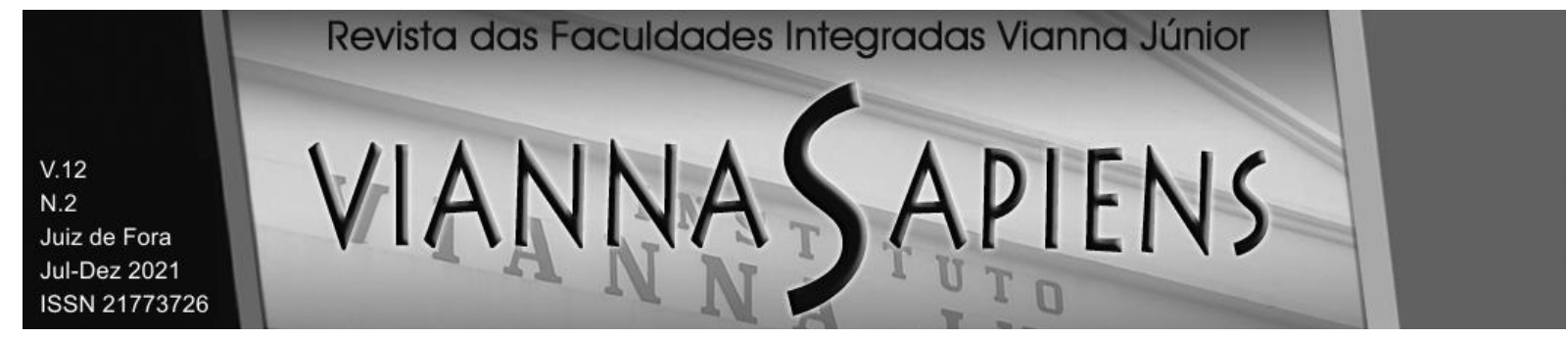

BARRETO, José Victor Souza. Fundos de investimento imobiliário no Brasil: as características que explicam o desempenho. Tese (Mestrado em Finanças e Economia) - Fundação Getúlio Vargas, São Paulo, p. 51, 2016.

BRASIL. Instrução CVM n. 409, de 18 de agosto de 2004. Dispõe sobre a constituição, a administração, o funcionamento e a divulgação de informações dos fundos de investimento. Disponível em:

http://conteudo.cvm.gov.br/legislacao/instrucoes/inst409.html. Acesso em: 08 de jul. 2021.

. Instrução CVM n. 555, de 17 de dezembro de 2014, com as alterações introduzidas pelas instruções CVM № 563/15, 564/15, 572/15, 582/16 e 587/17. Dispõe sobre a constituição, a administração, o funcionamento e a divulgação de informações dos fundos de investimento. Disponível em:

http://conteudo.cvm.gov.br/legislacao/instrucoes/inst555.html. Acesso em: 07 de jul. 2021.

Instrução CVM oㅜ 472, de 31 de outubro de 2008, com as modificações introduzidas pelas instruções CVM no 478/09, 498/11, 517/11, 528/12, 554/14, $571 / 15$ E 580/16. Dispõe sobre a constituição, a administração, o funcionamento, a oferta pública de distribuição de cotas e a divulgação de informações dos Fundos de Investimento Imobiliário - FII. Revoga as instruções CVM № 205, de 14 de janeiro de 1994, no 389, de 3 de junho de 2003, no 418, de 19 de abril de 2005 e no 455, de 13 de junho de 2007. Acrescenta o anexo III-B à instrução CVM no 400, de 29 de dezembro de 2003. Disponível em:

http://conteudo.cvm.gov.br/legislacao/instrucoes/inst472.html. Acesso em: 07 de jul. 2021.

CASTRO, Marcelo Augusto Farias. Co-integração na indústria de fundos imobiliários no Brasil. 2012. 52f. Dissertação (mestrado profissional) - Programa de Pós Graduação em Economia, CAEN, Universidade Federal do Ceará, Fortaleza, Ce, 2012.

CVM. Guia CVM do Investidor: Fundos de Investimento Imobiliários. COMISSÃO DE VALORES MOBILIÁRIOS (CVM). 2. ed. Rio de Janeiro, 2015. Disponível em: https://www.investidor.gov.br/publicacao/serie_guias/guia_CVM_FIl_2ed.pdf Acesso em: 08 de jul. 2021. 


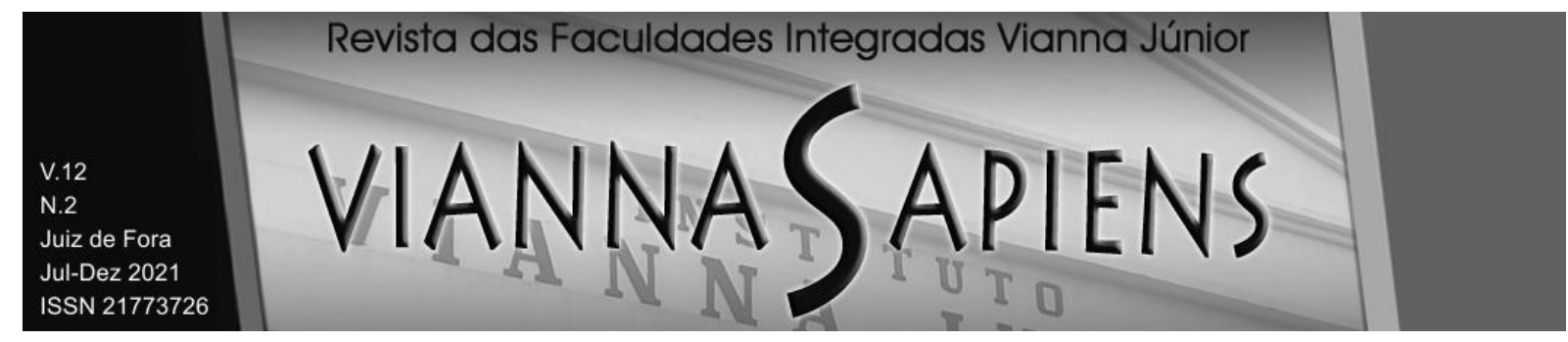

Guia CVM do Investidor: Fundos de Investimento Imobiliários.

COMISSÃO DE VALORES MOBILIÁRIOS (CVM). FUNDOS DE INVESTIMENTO. 3. ed. Rio de Janeiro, 2016. Disponível em:

https://www.investidor.gov.br/portaldoinvestidor/export/sites/portaldoinvestidor/public acao/Cadernos/CVM-Caderno-03-3ed.pdf acesso 09/07/2021. Acesso em: 08 de jul. 2021.

FIGUEIREDO FILHO, Fábio; AKKARI, Abla. Comportamento do Valor de Negociação das Cotas dos Fundos Imobiliários no Brasil no Período de 2013 a 2018. In: 19ª Conferência Internacional da LARES. São Paulo, 2019.

FIGUEIREDO FILHO, Dalson. et al. O que Fazer e o que Não Fazer com a Regressão: pressupostos e aplicações do modelo linear de Mínimos Quadrados Ordinários (MQO). Revista Política Hoje, Recife, v. 20, n. 1, p. 44-99, 2011.

FIORINI, Renato Maestre. Determinantes da Rentabilidade dos Fundos de Investimento Imobiliário no Brasil / Renato Maestre Fiorini. - 2012. 73 f. Orientador: Ricardo Ratner Rochman. Dissertação (MPFE) - Escola de Economia de São Paulo.

GIL, Antônio Carlos. Como Elaborar Projetos de Pesquisa. 5. ed. São Paulo: Atlas, 2016.

GROSS, Rodrigues Martim. Investimento de Longo Prazo no Mercado Imobiliário Brasileiro. 47 f. Dissertação (mestrado) - Escola de Economia de São Paulo, 2012.

GUIMARÃES, J. G. M. 2013. Persistência na performance de fundos de investimento imobiliário brasileiros entre 2008 e 2012. Rio de Janeiro, RJ. Dissertação de Mestrado. Fundação Getúlio Vargas, 2013.

HAIR, Joseph. F.; et al. Análise Multivariada de Dados. 6. ed. Porto Alegre: Bookman, 2009.

HIRANO, Felipe. Determinantes do desempenho de fundos de investimento imobiliário. Tese (Mestrado em Administração) Insper, São Paulo, 2018. 


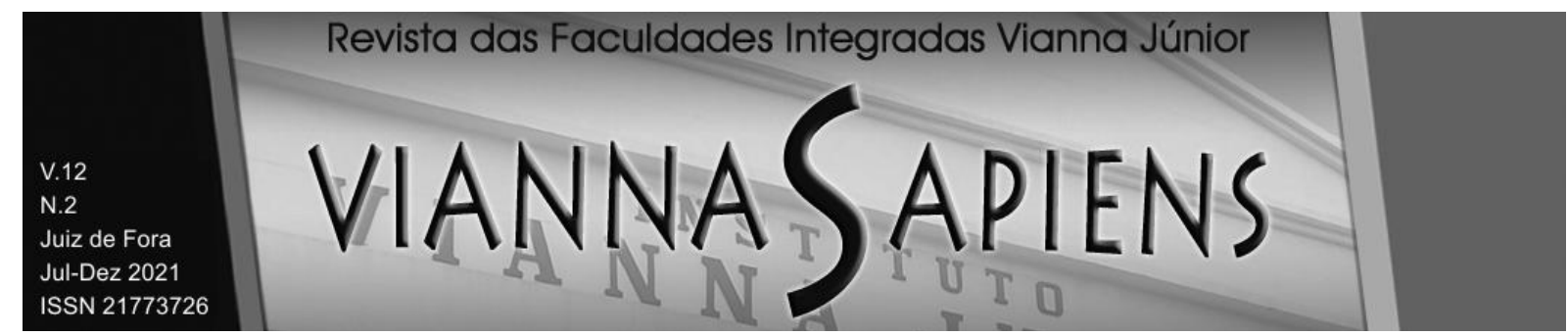

MALACO, André Scatolin. Uma análise da relação do desempenho de fundos imobiliários lastreados em shopping centers com variáveis macro e microeconômicas. Tese (Mestrado em Administração). Centro Universitário Álvares Penteado. São Paulo, 2020.

MINGIONE, Caio; DE BRITTO, Daniel Pitelli. Impacto da Crise de 2014 a 2017 no desempenho dos Fundos de Investimento Imobiliários brasileiros listados em bolsa. Latin American Real Estate Society (LARES), 2018.

MIZUNO, Jorge et al. Análise da eficiência dos fundos de investimentos imobiliários. Revista Pensamento Contemporâneo em Administração, v. 5, n. 1, p. 66-79, 2011.

OLIVEIRA, Janaína Morais; MILANI, Bruno. Variáveis que explicam o retorno dos fundos imobiliários brasileiros. Revista Visão: Gestão Organizacional, Caçador, SC, Brasil, v .9, n. 1, p. 17-33, 2020.

STEFFEN, Marcus Alexander. Rentabilidade dos fundos de investimento imobiliários: uma análise da influência da Bolsa de Valores, dos juros e de fatores específicos do mercado. Tese de Mestrado em Administração. Universidade de São Paulo, p. 151, 2015.

THEÓPHILO, Carlos Renato; MARTINS, Gilberto de Andrade. Metodologia da investigação científica para ciências sociais aplicadas. São Paulo: Atlas, v. 2, n. 104-119, p. 25, 2009.

TOGNINI, Felipe Baptista; DE ALENCAR, Claudio Tavares. Gestão ativa de portfólios em Fundo de Fundos de Investimento Imobiliários no Brasil. In $19^{\underline{a}}$ Conferência Internacional da LARES. Real Estate Fund of Funds Active Portfolio Management in Brazil. São Paulo, 2019.

VERGARA, Sylvia Constant. Projetos e relatórios de pesquisa em administração. 16. ed. São Paulo: Atlas, 2016 


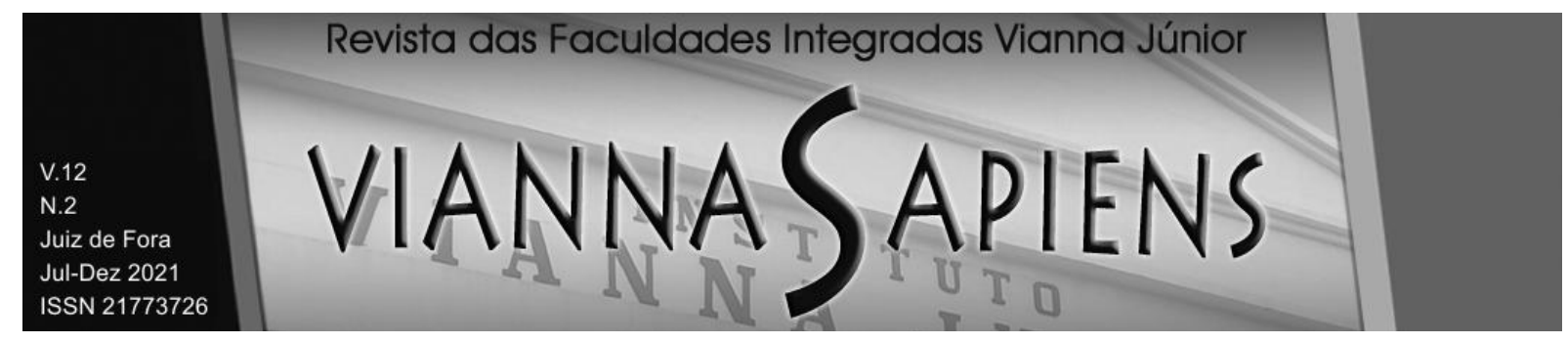

YOKOYAMA, Karen Yuraki. Os Fundos de Investimento Imobiliário Listados em Bolsa e as Variáveis que Influenciam seus Retornos. 81f. (Mestrado em Ciência Contábeis) - Centro de Ciências Jurídicas e Econômicas, Universidade Federal do Espírito Santo, Vitória, 2014.

Recebido em 13/07/2021

Publicado em 03/09/2021 